\title{
Identificação e Descrição das Primeiras Ferramentas de Controle Contábil Através da Ciberarqueologia
}

\author{
Identification and Description of the First Accounting Control Tools Through Cyber- \\ archeology
}

\author{
Paulo Schmidt \\ Doutor em Contabilidade e Controladoria pela Universidade de São Paulo \\ Professor da Universidade Federal do Rio Grande do Sul \\ Av. João Pessoa, 52 - sala 44. Porto Alegre, RS. CEP 90040-000 \\ Telefone: 51-33083312 \\ E-mail: pschmidt@ufrgs.br \\ José Luiz dos Santos \\ Doutor em Economia pela Universidade Federal do Rio Grande do Sul \\ Professor da Faculdade São Francisco de Assis \\ Av. Sertório, 253. Porto Alegre, RS. CEP 91020-001 \\ E-mail: joseluiz@,saofranciscodeassis.edu.br
}

\section{Resumo}

Esse estudo buscou descrever como as novas ferramentas cibernéticas estão contribuindo para o aprimoramento da compreensão de como os tokens e os envelopes de argila eram utilizados como ferramentas de controle contábil na sociedade pré-histórica. Para operacionalizar a identificação e descrição desse estudo, os dados foram capturados a partir da conjugação de duas modalidades de pesquisa: pesquisa bibliográfica e pesquisa documental. Os primeiros estudos sobre tokens e envelopes foram desenvolvidos, especialmente, por Mattessich, a partir das pesquisas da arqueóloga Schmandt-Besserat, porém, estavam voltados para uma análise arqueológica tradicional e sem o uso de ferramentas cibernéticas. $\mathrm{O}$ uso de tecnologias cibernéticas digitais criou novas perspectivas investigativas para estudos históricos, especialmente em áreas como a arqueologia. A digitalização das imagens dos tokens e dos envelopes permitiu que estudiosos de História da Contabilidade tivessem acesso mais fácil aos documentos, catálogos, repositórios e banco de dados, sem que o acervo histórico estivesse fisicamente disponível para análise. Para muitos acadêmicos seria impossível visualizar as peças contábeis históricas sem esse processo de digitalização. Além disso, a própria degradação das peças com o passar do tempo e com o manuseio dos pesquisadores está sendo mitigada com a digitalização e impressão de réplicas de tokens e envelopes em 3D. Ao mesmo tempo, os benefícios de escanear os envelopes, ao contrário de quebrá-los, não é apenas pela natureza não-destrutiva dos testes, mas pela capacidade de analisar a estrutura interna da argila, permitindo inspecionar as dobras, as inclusões e as mudanças de densidade na argila, produzindo indícios claros de como esses artefatos foram construídos. Portanto, a simulação real dos tokens e dos envelopes muda a compreensão do pesquisador, tendo na hiper-realidade virtual uma possibilidade de aprimorar a interação com o passado da Contabilidade.

Palavras-Chave: Controle Contábil, Tokens, Envelopes, Ciberarqueologia.

\section{Abstract}

This study sought to describe how the new cybernetic tools are contributing to the improvement of the understanding of how tokens and clay envelopes were used as tools of accounting control in the prehistoric society. To perform the identification and description of 
this study, the data were captured from the conjugation of two research modalities: bibliographic research and documentary research. The first studies on tokens and envelopes were developed, especially by Mattessich, based on the research of the archaeologist Schmandt-Besserat, but they were directed towards a traditional archaeological analysis and without the use of cybernetic tools. The use of digital cybernetic technologies has created new investigative perspectives for historical studies, especially in areas such as archeology. Digitizing the images of tokens and envelopes enabled Accounting History scholars to have easier access to documents, catalogs, repositories, and databases, without the historical stock being physically available for analysis. For many academics, it would be impossible to visualize historical accounting pieces without this digitization process. In addition, the actual degradation of the pieces over time and with the handling of the researchers is being mitigated by the scanning and printing of replica tokens and 3D envelopes. At the same time, the benefits of scanning envelopes, as opposed to breaking them, are not only the non-destructive nature of the tests, but the ability to analyze the internal structure of the clay, allowing you to inspect the folds, inclusions, and changes of density in the clay, producing clear indications of how these artifacts were constructed. Therefore, the actual simulation of the tokens and the envelopes changes the researcher's understanding, having in the virtual hyper-reality one enables to improve the interaction with the past of Accounting.

Keywords: Accounting, Tokens, Envelopes, Cyber-archeology.

\section{Introdução}

A evolução tecnológica dos últimos anos tem impactado diretamente na forma de como muitos pesquisadores têm buscado novas evidências para suas investigações.

Como afirma Rangel (2012), nos últimos anos áreas das humanidades e das ciências sociais sofreram transformações relevantes, com a adição de novas tecnologias na formação do conhecimento científico.

A incorporação de modernas tecnologias em áreas como a História, fez como que a busca por evidências e explicações para os acontecimentos passados ganhassem novas facetas, especialmente em abordagens de pesquisas arqueológicas da Cultura Material.

A Cultura Material, segundo Azevedo Netto e Souza (2010), tornou-se um referencial para análise de vínculos de identidades históricas, alterando ao longo do tempo a forma de analisar a memória, ocupando um lugar de destaque no campo arqueológico, passando a atuar além da busca da mera descrição dos artefatos históricos, para analisar a forma como esses artefatos resultaram como um produto do comportamento humano. Para Azevedo Netto e Souza (2010), o registro arqueológico não pode ser visto apenas como algo passível somente de descrição, mas como um elemento fundamental que representa comportamentos culturais passados, que devem ser analisados a partir dos fundamentos teóricos disponíveis, para o aprofundamento do entendimento da dinâmica sociocultural que os produziu.

Essa mudança de percepção dos fatos históricos ocorrida, principalmente, a partir do surgimento da chamada Nova História, como destaca Burke (1992), fez com que as pesquisas histórias passassem a se interessar por toda a atividade humana, não apenas pelos grandes homens e líderes mundiais, mas com as opiniões das pessoas comuns, onde a história passou a ser explicada por outras fontes e não apenas por documentos tradicionais, onde o historiador passou a assumir a dificuldade de explicar como os fatos realmente aconteceram.

Associado a essas mudanças no campo da pesquisa histórica, a inclusão de novas ferramentas de análise e comunicação dos estudos, especialmente na Cultura Material, desencadeou novas perspectivas para a avaliação da origem dos fatos históricos da humanidade. 
Nesse novo contexto, novos campos de estudos passaram a ser incorporados em várias dimensões interdisciplinares da pesquisa histórica, como é o caso da inclusão de conhecimentos da Cibernética, do Ciberespaço, da Cibercultura e da Inteligência Cibernética.

A Arqueologia não se furtou desses novos paradigmas e passou a incluir nos seus processos investigativos vários aspectos da inteligência cibernética, tanto que criou a chamada Ciberarqueologia. De acordo com Martire (2014), Ciberarqueologia está focada na análise de ambientes tridimensionais interativos do passado através da interação entre a Realidade Virtual e a Arqueologia.

A Ciberarqueologia tem empregado ferramentas de tecnologia avançada que, segundo Ngo (2017), tem permitido que pesquisadores aprofundem a compreensão do significado do uso de artefatos de argila para registro e controle patrimonial encontrados em sítios arqueológicos de civilizações mesopotâmicas. Conforme Ngo (2017), pesquisadores do Instituto Oriental da Universidade de Chicago têm utilizados tomografia computadorizada para digitalizar imagens de 18 esferas de argila escavadas em Choga Mish, no Irã. Essas esferas de argila serviam para arquivar pequenas fichas, também de argila, denominadas de tokens.

O estudo dos tokens, especialmente dentro de uma visão histórica tradicional, já foi explorado por pesquisadores nas áreas de história e da contabilidade, como é o caso de Mattessich (1987, 1989, 1994, 1997, 1998, 2000), que retratou estudos sobre as evidências arqueológicas da contabilidade pré-histórica, de Hopwood (1987), que apresentou uma pesquisa sobre a arqueologia dos sistemas de contabilidade, e de Schmandt-Besserat (1977, 1979, 1989, 1992, 2002, 2009a, 2009b, 2010, 2012, 2014), que direcionou seus estudos para identificar a origem da escrita e da numerologia através da pesquisa com tokens.

Os estudos de Mattessich (1987, 1989, 1994, 1997, 1998, 2000), retratam, a partir das pesquisas de Schmandt-Besserat, interpretações do ponto de vista contábil, defendendo a origem da contabilidade a partir dos achados arqueológicos de Schmandt-Besserat, embora essa arqueóloga não tenha sido motivada na busca dos primeiros sinais de controle contábil e sim na busca da origem da escrita e do uso dos números pelas civilizações pré-históricas.

Muitos desses estudos iniciados na década de 1980, foram desenvolvidos num ambiente de pesquisa com tecnologia analógica, gerando dificuldades de aprofundamento de análise e de divulgação das descobertas arqueológicas da origem da Contabilidade.

Porém, segundo Moreno (2013, p. 115), “as telecomunicações são quase integralmente digitais desde 1990 e a maioria da nossa memória tecnológica (94\%) já estava em formato digital no ano de 2007". Esse novo ambiente de disseminação de tecnologia digital vivido a partir dos anos de 1990, trouxe para a Ciberarqueologia novas possibilidades de compreensão e divulgação, sobretudo para os estudos da Cultura Material.

Assim, considerando o atual ambiente digitalizado, dentro desse contexto cibernético, como essas novas tecnologias estão contribuindo com o refinamento das investigações que buscam aprimorar a identificação e descrição do uso de artefatos pré-históricos de argila que caracterizaram os primeiros sinais de controle contábil criado pelo ser humano?

Esse estudo intenta, portanto, dentro dessa nova realidade de investigação científica e tecnológica, identificar e descrever quais ferramentas cibernéticas estão contribuindo para o aprimoramento da compreensão da forma como os tokens e os envelopes de argila eram utilizados como ferramentas de controle contábil na sociedade pré-histórica.

Do ponto de vista científico, a análise do uso da Ciberarqueologia, conforme destaca Martire (2017), possibilita a ligação virtual entre o objeto analisado (tokens e envelopes) e o ambiente, através de um processo de simulação, reinterpretando o passado no espaço e no tempo. As ferramentas da Ciberarqueologia, destaca Martire (2017), propicia a interação de mundos virtuais, permitindo novas interpretações sobre o passado. Portanto, mesmo que esse passado não possa ser reconstruído, ele pode ser simulado tridimensionalmente. 
As buscas pela ampliação do conhecimento sobre a forma como as primeiras ferramentas de controle patrimonial foram criadas e como eram utilizadas pela sociedade préhistórica, através do uso de ferramentas da Ciberarqueologia, permite simular virtualmente o comportamento dinâmico da gênese desses controles, possibilitando vislumbrar como a sociedade passada utilizava essas ferramentas e entender a sua importância para o convívio em comunidade. Porém, esse ensaio teórico não busca pela origem da contabilidade, mas pelos primeiros sinais de uso de ferramentas de controle, considerando, que a pesquisa histórica busca "...evidências coordenadas e interpretadas, exigindo do pesquisador o trabalho de suplantar sua própria contemporaneidade sem deixar-se cair, entretanto, num historicismo que se traduziria em anacronismo, numa interpretação errônea, distorcida do passado". (PIMENTEL, 2001, pg. 192).

Para atingir o intento proposto, esse ensaio teórico inicia com uma visão geral sobre as primícias do controle contábil, dividido na apresentação da origem dos primeiros sinais de controle patrimonial, dos tokens como ferramentas de controle contábil e do uso dos envelopes como ferramenta de guarda dos tokens, passando para a exposição dos procedimentos realizados na pesquisa, seguindo com o destaque para a apresentação de uma seção sobre o uso da Ciberarqueologia para avaliação dos tokens e dos envelopes de argila, dividida na análise da Ciberarqueologia e na análise dos tokens e dos envelopes e nas contribuições das ferramentas cibernéticas para essa análise, encerrando com as considerações finais.

\section{As Primícias do Controle Contábil}

A identificação das primeiras imagens sobre a origem primitiva dos primeiros sinais do uso de ferramentas de controle patrimonial pelo homem pré-histórico, passa, preliminarmente, pelo entendimento de quando o homem surgiu na terra. Segundo Antón, Potts e Aiello (2014), os cientistas acreditam que muitas das características dos seres humanos teriam surgido no gênero Homo entre 2,4 e 1,8 milhões de anos atrás, na África, embora, evidências fósseis sugerem que esses traços não surgiram como um único pacote, mas, em vez disso, vários ingredientes-chave que se acredita terem definido o Homo, evoluíram em ancestrais anteriores, o Australopitecos, entre 3 e 4 milhões de anos atrás.

Para Severinghaus e Brook (1999), o fim do último período glacial propiciou o surgimento das primeiras civilizações, em função do aquecimento do planeta, há aproximadamente 15.000 anos atrás, gerando um clima mais quente e úmido, permitindo ao homem a sua socialização e fixação em terras férteis, proporcionando a criação das primeiras cidades.

Uma cidade pode ser definida, segundo Mark (2017), como um grande povoado urbano de comércio e administração com um sistema de leis e, geralmente, meios regulamentados de saneamento.

Para Mark (2017), as primeiras cidades que se encaixam nessas definições foram descobertas na região conhecida como Mesopotâmia entre 4.500 e 3.100 a.C., sendo a cidade de Uruk hoje considerada a mais antiga do mundo, fundada em 4.500 a.C.

Uruk, completa Mark (2017), é a única concorrente para o título de cidade mais antiga, que tem provas materiais e documentação escrita, sob a forma de textos cuneiformes, registrados a partir das primeiras atividades da comunidade, sendo que em sítios como Jericó, Sidon e Eridu, que se instalaram antes Uruk, faltam o mesmo tipo de documentação.

As primeiras cidades permitiram a socialização do ser humano e a necessidade de aumento na produção de alimentos. Para Burke e Ornstein (2017), uma maior eficiência de cultivo de alimentos fez com que o homem passasse a fixar residência e criasse laços mais fortes em determinadas localidades. 
A produção de alimento em excesso e o aumento da eficiência na produção agrícola, como defendem Burke e Ornstein (2017), fez com que as pessoas não envolvidas diretamente na produção de alimentos, passassem a exercer outras atividades, tais como a produção de ferramentas, de cestas e outras artes que começaram a ser praticadas em maior escala. Essas mudanças sociais geraram a necessidade da criação de novos níveis organizados de sobrevivência necessários ao convívio das pessoas.

O excedente na produção de alimentos, segundo Burke e Ornstein (2017), gerou um novo fenômeno ainda não vivido pela sociedade primária: o excesso de alimentos poderia ser armazenado, comercializado ou utilizado como pagamentos de bens e serviços, gerando a necessidade da criação de formas rudimentares de controles e registros.

\subsection{A Origem dos Primeiros Sinais de Controle Patrimonial}

A partir dessa nova realidade que o homem pré-histórico passou a viver, novas oportunidades, bem como, novas necessidades passaram a fazer parte de sua vida cotidiana. Dentre as novas necessidades, a de controlar seu patrimônio foi uma das mais marcantes.

As primeiras ferramentas criadas para registro de controle patrimonial, segundo Burke e Ornstein (2017), parecem ter sido inventadas há 12.000 anos nas Montanhas Zagros (cordilheiras situadas entre os países do Irã e Iraque). Essas primeiras ferramentas foram representadas por fichas (tokens) de argila simples que correspondiam a diferentes produtos. Seu uso, como afirmam Burke e Ornstein (2017), se espalhou por todo o Oriente Médio desde então, até cerca de 5.400 anos atrás.

Uma das primeiras imagens conhecidas de tokens relacionadas com estudos contábeis, foram apresentados por Mattessich em 1994, fazendo referência ao estudo de SchmandtBesserat, onde são apresentados os tipos de tokens e a suas referências em escrita pictográfica, conforme figura 1. No exemplo, Mattessich (1994) apresenta na primeira coluna a forma de como era representado o token e na segunda como o patrimônio era representado em escrita pictográfica. Os tokens representavam (figura 1 de cima para baixo): uma medida de pão, uma medida de óleo, um alimento não especificado, uma medida de doce, provavelmente mel, e um objeto têxtil.

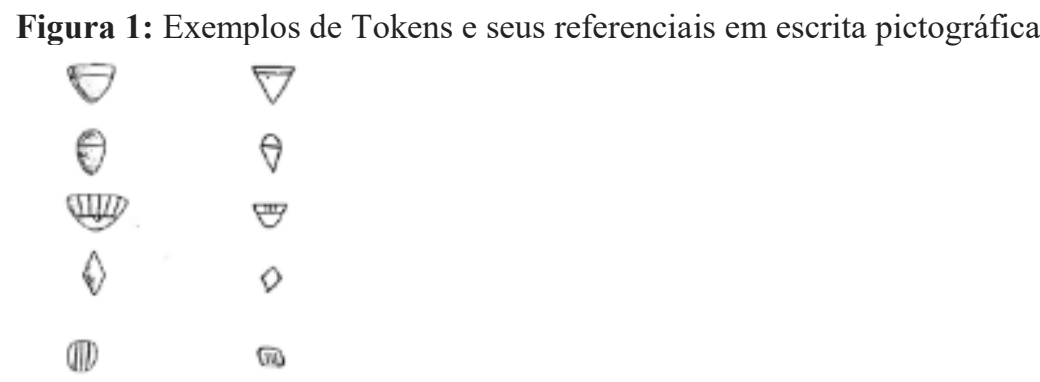

Fonte: Mattessich (1994)

Na Figura 2 são apresentadas imagens com mais qualidade, embora ainda com pouco detalhamento, de tokens encontrados em regiões da Síria e Irã, datados de 8.000 a 3.500 a. C., do período Neolítico (considerado o último período pré-histórico), também denominado de Nova Idade da Pedra ou Idade da Pedra Polida. Esta figura, segundo Schøyen (2017a), descreve alguns tokens que, possivelmente, representavam uma medida de grãos, um animal e um homem ou um dia de trabalho, representados por três esferas de 1,6, 1,7 e 1,9 $\mathrm{cm}$, dois tetraedros de 1,4 e $1,7 \mathrm{~cm}$ e três discos medindo $1,0 \times 0,4 \mathrm{~cm}, 1,1 \times 0,4 \mathrm{~cm}$ e $1,0 \mathrm{x}$ $0,5 \mathrm{~cm}$. Esses tokens estão no acervo do The Norwegian Institute of Palaeography and Historical Philology, na cidade de Oslo, Noruega. 
Figura 2: Imagens de Tokens do período Neolítico

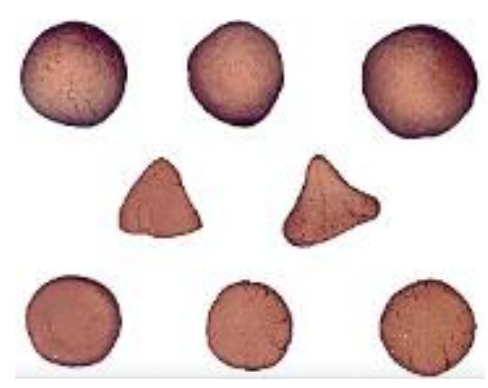

Fonte: Schøyen, M. (2017a)

Para Schøyen (2017a), há cerca de 8.000 a. C. os tokens passaram a substituir as contagens da forma mais simples, ou seja, a correspondência um-para-um, por meio da substituição por símbolos neolíticos de várias formas geométricas objetivando a contagem concreta, dependendo do tipo de ativo que deveria ser controlado. Esses tokens, segundo Schøyen (2017a), inicialmente, adotaram formas geométricas básicas, como esferas, tetraedros, cones, cilindros, discos, quadriláteros, triângulos etc. Eles eram guardados em cestas, potes de couro, tigelas de argila etc.

\subsubsection{Tokens como ferramentas de controle contábil}

Durante décadas, segundo Lawler (2001), arqueólogos no Iraque, Síria e Irã desenterram numerosos tokens com diversas formas geométricas, com idades que variavam de cerca de 4.000 a 9.000 anos. Além dos tokens, eles também encontraram esferas ocas de argila, com marcações do lado de fora, que serviam de uma espécie de cofre para guardar as fichas.

A tese de que os tokens faziam referência a um determinado objeto, foi proposta, segundo Buccellati (2017) e Schroeder (1980), pela primeira vez em 1966, por Pierre Amiet um arqueólogo do museu do Louvre de Paris. Ele apontou a ligação conceitual entre os tokens e objetos individuais.

A teoria de Pierre Amiet foi aprimorada por sua aluna: a arqueóloga Denise Schmandt-Besserat, professora da Universidade do Texas, Austin.

O foco inicial do trabalho de Denise Schmandt-Besserat estava direcionado para a identificação dos primeiros sinais de desenvolvimento da escrita e da contagem abstrata pelo homem pré-histórica, mas, segundo Mattessich (1994, p.7), acabou "...tropeçando na origem da Contabilidade".

Para Schmandt-Besserat (2009a), antes de estudar o significado cognitivo do sistema de tokens, é importante entender a origem e formação cultural da região. Para SchmandtBesserat (2009a), os tokens começaram a aparecer no Crescente Fértil do Oriente Próximo, onde estão atualmente situados a Síria e o Irã, em torno de 7.500 a. C. Isto significa que a contagem coincidiu com a agricultura, e em particular, com a economia de redistribuição dos excedentes da agricultura. Tokens, segundo Schmandt-Besserat (2009a), provavelmente, foram utilizados para reunir os excedentes comunitários para a preparação das festas religiosas que constituíram o eixo central da economia de redistribuição. Os tokens ajudavam os líderes comunitários a manterem o controle dos bens recolhidos dos cidadãos e sua redistribuição como oferendas aos deuses e as várias necessidades da comunidade.

Os tokens eram utilizados não apenas para controle patrimonial dos bens, mas, como o homem ainda não havia desenvolvido a contagem abstrata, eram também utilizados para contagem concreta, especialmente de medidas de grãos, de frascos de óleo, de animais e de unidades de trabalho em tempo e tarefas. 
Schmandt-Besserat (2009a) defende que a forma de representação dos objetos era muito variada. Como exemplo, demonstra que a representação de grãos em pequenas quantidades era por meio de um token com formato de cone e em grandes quantidades na forma de esferas, de óleo na forma de ovoides, de animais como cilindros e de unidades de trabalho com tetraedros. A Figura 3 apresenta exemplos de tokens mais complexos descritos por Schmandt-Besserat (2009a), que representam fichas (de cima, da direita para a esquerda) uma ovelha, um frasco de óleo, um lingote de metal, uma peça de vestuário, (abaixo, da direita para a esquerda) uma peça de vestuário, um item não identificado, um favo de mel, encontrados em Susa, Irã, datados de cerca de 3.300 a. C. Esses tokens se encontram expostos no museu do Louvre, no Departamento de Antiguidades Orientais, em Paris.

Figura 3: Exemplos de tokens descritos por Schmandt-Besserat

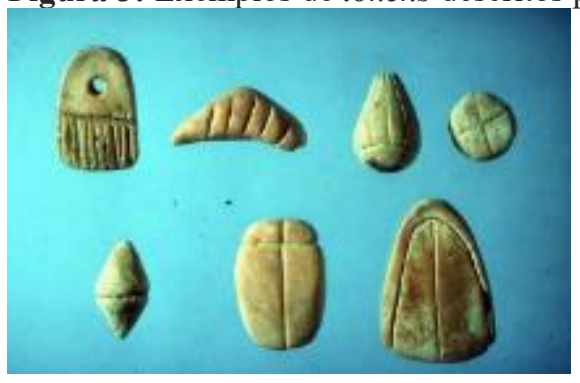

Fonte: Schmandt-Besserat (2009a).

O número de formas de tokens, segundo Schmandt-Besserat (2009a), era limitado a cerca de 12 em torno de 7.500 a. C., aumentando para cerca de 350 por volta de 3.500 a. C., quando começaram a aparecer as primeiras oficinas urbanas contribuindo para a economia de redistribuição de bens.

Alguns dos novos modelos de tokens passaram a representar matérias-primas como a lã e o metal, enquanto outros representavam produtos acabados, tais como têxteis, vestuário, joias, pão, cerveja e mel. Os tokens mais complexos assumiram as formas dos itens que simbolizavam, tais como roupas, vasos em miniatura, ferramentas e mobiliário.

Os artefatos mais complexos, segundo Schmandt-Besserat (2009a), levaram muito tempo e necessitavam mais habilidade para serem modelados em comparação com os antigos de formas geométricas, como cones e esferas, o que sugere que especialistas foram os responsáveis por fabricá-los. A Figura 4 apresenta alguns exemplos de tokens mais complexos, desenvolvidos a partir dos modelos mais simples, assumindo, na visão de Schøyen (2017b), novas formas, linhas, pontos e vários novos formatos para atender as necessidades mais avançadas de controle patrimonial.

Figura 4: Exemplos de Tokens mais complexos

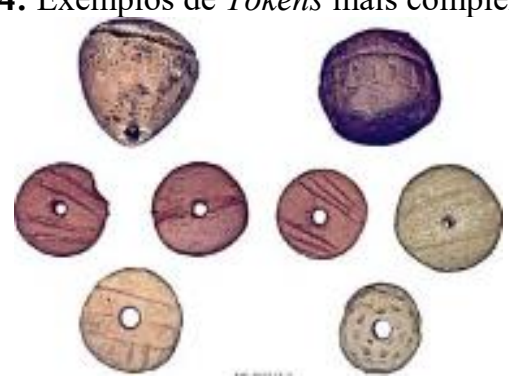

Fonte: Schøyen (2017b)

Uma das principais peculiaridades dos tokens, para Schmandt-Besserat (1977), é a característica de tamanho pequeno, presente em todos os modelos, medindo em média de um a dois centímetros. A coloração dos tokens poderia variar entre cor de argila, vermelho, cinza 
ou preto.

A importância do uso dos tokens como ferramenta de controle patrimonial pela civilização pré-histórica, foi de grande importância, tanto que Schmandt-Besserat (2009a) é enfática ao afirmar que, por volta de $3300 \mathrm{a}$. C, os tokens ainda eram os únicos dispositivos da Contabilidade para gerir a economia de redistribuição de ativos dos templos administrados pelos sacerdotes. Schmandt-Besserat (2009a) acrescenta, que a oferta de ativos para os templos era comum, especialmente para a preparação de festivais, porém, a frequência da entrega e os tipos de bens e suas quantidades passou a ser regulada e o não cumprimento pela população passou a ser penalizado. Essa nova realidade social desencadeou um novo desafio para a Contabilidade primitiva: a invenção de ferramentas menos frágeis para o controle patrimonial, surgindo os chamados envelopes, onde os tokens, especialmente das contas dos inadimplentes, pudessem ser mantidos em segurança até que as dívidas fossem pagas.

\subsubsection{O Uso dos envelopes como ferramenta de guarda dos tokens}

A evolução da complexidade da sociedade mesopotâmica trouxe consigo alguns desafios aos responsáveis pelo controle patrimonial dessa sociedade. Um dos novos desafios foi a criação de envelopes de argila para guarda dos tokens.

Os tokens eram, inicialmente, guardados em cestos de vime, em caçarolas de couro, em tigelas de barro, porém, nenhum desses utensílios garantiam que os artefatos não seriam extraviados. Buscando uma maior segurança na guarda dessas peças, os homens pré-históricos criaram uma ferramenta para garantir que os tokens não seriam extraviados: os envelopes de argila.

Algumas teorias foram desenvolvidas para explicar a utilização dos envelopes de argila. Schmandt-Besserat (2009a), por exemplo, relata que o montante de tokens era colocado em bolas de argila ocas e, para mostrar o conteúdo dos envelopes, os responsáveis pela guarda dos artefatos passaram a marcar na parte exterior dos envelopes os tokens que foram colocados no seu interior, além de estamparem selos de segurança, enquanto a argila ainda não estava seca.

Essa marcação exterior resolveu um problema que inicialmente existia que era a verificação de quais peças foram colocadas no interior dos envelopes. A única forma de verificar o interior dos envelopes, seria quebrá-los, anulando as garantias. Schmandt-Besserat (1977b) aponta que esse problema foi resolvido, imprimindo na superfície do envelope uma série de marcas que representam a forma e o número de tokens que haviam sido colocados no seu interior. Muitas vezes, afirma Schmandt-Besserat (1977), as marcações eram feitas de forma grosseira e em cima dos selos, às vezes pressionando-os na superfície ainda molhada do envelope de argila os mesmos tipos e quantidades de tokens que haviam sido colocados no seu interior. Para essa impressão poderiam ser utilizados os dedos ou instrumentos pontiagudos.

Estas inscrições externas, na opinião de Schmandt-Besserat (1977), poderiam ser identificadas por qualquer pessoa que tivesse o conhecimento do sistema simbólico utilizado nos tokens contábeis.

A figura 5 apresenta um envelope que contém 11 tokens complexos, representando segundo Schøyen (2017c), contas ou acordos de salários de trabalhadores, medidas de algum metal, medidas grandes de cevada e medidas pequenas de alguma outra mercadoria. $\mathrm{O}$ conjunto completo de tokens simples e complexos era composto de 4 tetraedros de $0,9 \times 1,0$ $\mathrm{cm}, 4$ triângulos com 2 linhas incisas de 2,0x0,9 cm, 1 esfera de 1,7 cm de diâmetro, 1 cilindro de 2,0x0,3 cm e 1 paraboloide de 1,3 cm, com diâmetro de 0,5 cm. Esse envelope está no acervo do The Norwegian Institute of Palaeography and Historical Philology, na cidade de Oslo, Noruega. 
Figura 5: Exemplo de envelope com 11 Tokens complexos no seu interior

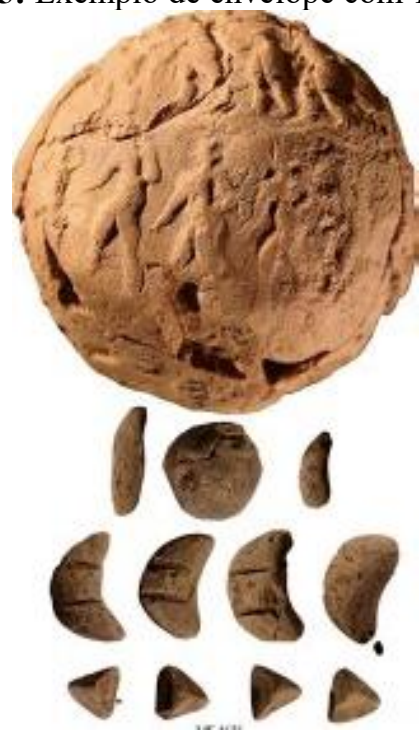

Fonte: Schøyen (2017c)

Essa esfera de argila que mede $6,5 \mathrm{~cm}$ de diâmetro, possui uma impressão externa, que caracteriza um selo de garantia (figura 6), representando uma fileira de homens caminhando à esquerda e de um predador atacando um veado.

Figura 6: Detalhe do selo horizontal que aparece no envelope da figura 4

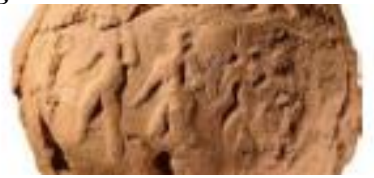

Fonte: Schøyen (2017c)

Conforme Schøyen (2017c), somente 25 envelopes foram encontrados em escavações na região de Uruk. O número total de envelopes já descobertos em todo o mundo é de 165 intactos e 70 fragmentados. Os envelopes não tinham dimensões fixas, podendo variar do tamanho de uma bola de golfe ao de uma bola de basquete.

Dentre os envelopes encontrados em escavações em sítios arqueológicos na Síria e no Irã, foi encontrado um (figura 7) que possuía 17 tokens e foi, até hoje, segundo Schøyen (2017d), o artefato que possuía o maior número de fichas. Esse envelope datava, segundo informações do museu Schøyen (2017d), entre 3700 e 3200 a.C., medindo $7 \mathrm{~cm}$ de diâmetro, com selos impressos na parte externa caracterizando uma fileira de homens, cada um carregando um saco em sua cabeça para um grande caldeirão colocado em um suporte arredondado e outro selo apresentando uma linha de anéis no alto da esfera com a figura de homens. Além desses selos de segurança, esse envelope possui uma terceira impressão de um token de um tipo de disco grande ou o fundo de um grande cone, com diâmetro de $2,2 \mathrm{~cm}$, podendo representar o conjunto de tokens colocados no seu interior. Esse envelope armazenava tokens representados por 1 esfera com diâmetro de $1,5 \mathrm{~cm}, 8$ esferas pequenas com diâmetros de $0,8 \mathrm{~cm}, 5$ cones de 1,0 x1,5 cm e 3 cilindros de 0,4 x1,2 cm. 
Figura 7: Exemplo de envelope com 17 Tokens no seu interior

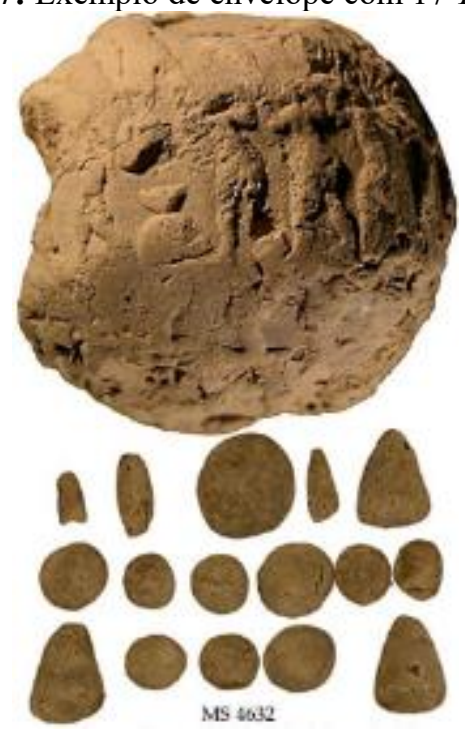

Fonte: Schøyen (2017d)

Esses 17 tokens, na interpretação dos pesquisadores do museu Schøyen (2017d), representavam contas de 300 dias de salários de trabalhadores ou o direito de um trabalhador por 300 dias trabalhados, com uma taxa de 1,8 medidas de cevada por homem/dia de trabalho, totalizando salários que equivaliam a 540 medidas de cevada. Esse processo de registro era cercado de controles para garantir que a transação não sofresse nenhum tipo de alteração.

Muitos dos envelopes analisados, segundo Woods (2012), possuíam selos externos que corriam no meio do envelope em linha horizontal (conforme figura 6) e, em muitos casos, com um outro selo de uma linha correndo de cima para baixo no sentido vertical. Woods (2012) acrescenta a hipótese de que, com base nessas evidências históricas, os selos horizontais no meio do envelope poderiam representar um comprador ou um destinatário das mercadorias, enquanto que selos verticais poderiam representar o vendedor ou distribuidor ou talvez terceiros que teriam participado na operação ou atuaram como testemunhas.

No antigo Oriente Médio, era costume, como aponta Schmandt-Besserat (2009a), tanto para os indivíduos, como para os estabelecimentos administrativos, possuírem uma pequena pedra esculpida com um padrão distinto que servia como uma marca de identificação. Esse mesmo padrão de garantia, passou a ser adotado nos envelopes, com a colocação de marcas, na forma de selos, para assinar e autenticar as transações. SchmandtBesserat (2009a) sugere que alguns envelopes poderiam ser cobertos com até três ou quatro selos distintivos, sugerindo o uso de testemunhas para as transações, bem como o uso em possíveis cópias de envelopes, que eram enviados com emissários para realizar transações em outras localidades, além de servirem de garantia de outras informações, como dívidas, recibos de impostos e venda de terras.

Na opinião de Woods (2012), os envelopes passaram a representar dispositivos que serviam de recibos de transações que envolviam venda de ativos, mediante a emissão do recibo de argila do valor e dos bens que estavam envolvidos na transação, considerando que, na opinião dele, existia uma maior necessidade de controle dos valores transacionados do que dos ativos que estavam nas mãos dos vendedores.

Além de vários tipos de selos de garantia, os envelopes poderiam variar de formato, como é o caso da Figura 8, que apresenta um modelo de envelope oval, medindo 2,5 cm por $6,5 \mathrm{~cm}$, com uma corda presa nas extremidades, que, segundo Schøyen (2017e), possui um selo que representa uma linha de animais andando para a esquerda e com dois homens de pé com os braços levantados. 
Figura 8: envelope oval com uma corda presa nas extremidades

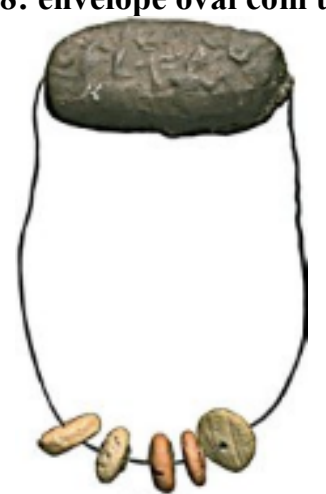

Fonte: Schøyen (2017e)

Esse envelope, que foi originalmente bloqueado nas extremidades com uma corda, possui um conjunto de tokens complexos. Para Schøyen (2017e), esse envelope representa uma transação com materiais têxteis, tendo no selo a garantia de que nem o envelope e nem número de tokens pudessem ser violados ou quebrados.

\section{Procedimentos de Pesquisa}

As determinações dos procedimentos de uma pesquisa contábil histórica devem seguir, conforme afirmam Carnegie e Napier (2016), às normas disciplinares da ciência social e, ao mesmo tempo, adotar os métodos de pesquisa de um trabalho histórico profissional. Para eles, os historiadores da contabilidade de hoje estão conscientes de que não começarão a entender a importância de um evento específico de um registro contábil, por exemplo, sem a compreensão de seu contexto organizacional e temporal mais amplo.

Para Carnegie e Napier (2016), os historiadores contábeis atuais estão mais dispostos a examinar as várias formas de evidências de uso da Contabilidade, em vez de simplesmente procurar examinar provas formais do uso histórico das partidas dobradas.

Essa ampliação do campo de análise dos estudos históricos da Contabilidade insere-se no contexto apresentado por Carmona, Ezzamel e Gutiérrez (2016), onde os estudos da chamada Nova História encaram a Contabilidade como um fenômeno cultural e social e não apenas como uma área do conhecimento voltada apenas para a geração de informações para o controle e tomada de decisão.

Para Fontoura, Alfaia e Fernandes (2013), os pesquisadores que utilizam métodos históricos de pesquisa devem considerar que os eventos históricos analisados não são passíveis de uma completa reprodução, exigindo que seja compreendido os principais aspectos conjunturais envolvidos no estudo.

Os estudos de natureza sócio histórica, como um estudo histórico da Contabilidade, devem adotar uma abordagem sistemática por meio de coleta, organização e avaliação crítica de dados de ocorrências do passado, conforme defendem Padilha e Borenstein (2005). A operacionalização desse tipo de estudo passa pela captura de dados a partir, normalmente, da conjugação de pesquisa bibliográfica e de documentos.

A pesquisa bibliográfica, segundo Oliveira (2016), é uma categoria de investigação que utiliza documentos de domínio científico, tais como: livros, periódicos, enciclopédias, ensaios críticos, dicionários e artigos científicos. Nessa categoria de investigação, o pesquisador, conforme Oliveira (2016), utiliza estudos de fontes de domínio científico, sem necessidade de recorrer diretamente aos fatos e fenômenos da realidade empírica.

A pesquisa de documentos, complementa Oliveira (2016), caracteriza uma busca de informações em documentos que não receberam tratamento científico, tais como relatórios, reportagens de jornais, revistas, cartas, filmes, gravações, fotografias, slides, pôsteres, 
imagens, sons, ilustrações, bem como todo tipo de artefato, entre outras fontes primárias, utilizados para qualquer tipo de ferramenta de divulgação.

Esse ensaio teórico, com característica descritiva de natureza qualitativa, segue o que Rangel (2012) defende para as atuais pesquisas históricas: os pesquisadores devem atentar para o uso de tecnologias para captura de dados bibliográficos e documentais, especialmente na área da História da Cultura Material, mediante o uso de ferramentas de captura de dados disponíveis na Internet, nos Metadados e nos Repositórios Digitais dos mais variados segmentos, dentre eles os museus que mantém salas e arquivos virtuais.

Esse estudo se caracteriza como um ensaio teórico, pois, conforme descreve Meneghetti (2011, pg. 324), "o ensaio permite a tentativa de compreender o fenômeno para conhecer o objeto, assim como permite analisar o próprio fenômeno para modificar a compreensão do objeto". Em um ensaio teórico, o objeto da pesquisa, quando relacionado com um elemento histórico, não deve se subordinar à totalidade da história, caracterizando um mero objeto funcional em um determinado contexto, onde se procura ampliar a compreensão que se tem desse objeto, mas deve ser implementado um movimento mais amplo na busca da razão como ato de reflexão. (MENEGHETTI, 2011). Dentro desse contexto histórico e reflexivo, esse ensaio teórico buscou identificar e descrever quais as ferramentas cibernéticas que estão sendo utilizadas pelos arqueólogos na busca do aprimoramento da compreensão da forma como os tokens e os envelopes de argila eram utilizados como ferramentas de controle contábil na sociedade pré-histórica.

O procedimento de análise bibliográfica e de documentos adotado nesse ensaio teórico busca ir além da análise tradicional focada no princípio de controle patrimonial e no uso de contas contábeis para controle da gestão. O uso desses novos instrumentos de investigação possibilita que se tenha uma abordagem mais ampla na identificação e descrição da gênese das ferramentas de controle, permitindo a identificação de algumas consequências sociais para o homem pré-histórico a partir da adoção dos tokens e dos envelopes de argila.

Dentre os repositórios digitalizados disponíveis utilizados para pesquisa de tokens e envelopes o do The Oriental Institute of the University of Chicago, dos Estados Unidos da América do Norte, foi um dos que mais contribuiu com imagens para o estudo. As imagens que foram compradas do The Oriental Institute estão creditadas com a informação: "Cortesia The Oriental Institute of the University of Chicago", por exigência do instituto.

\section{O Uso da Ciberarqueologia para Avaliação dos Tokens e dos Envelopes de Argila}

A análise tradicional dos artefatos históricos, segundo Zimansky (1993), passa por obstáculos para realização de testes em função da incapacidade de analisar de uma maneira não invasiva o conteúdo dos envelopes de argila. Robson (2004) complementa ao defender que o uso de tokens caracteriza um sistema coerente, porém, afirma que é difícil identificar objetos anteriores a 3.500 a. C, pois a maioria são pequenas bolas com saliências e é difícil saber se são tokens, pérolas ou pesos.

Em função dessas dificuldades da análise tradicional dos artefactos de argila, pesquisadores interessados em aprofundar o entendimento das funções contábeis dessas ferramentas, passaram a incorporar novas tecnologias no processo investigativo.

O uso de tecnologias para análise dos envelopes de barro não é um procedimento recente. Conforme Schmandt-Besserat (1977), o uso de equipamentos de Raio X para análise de um envelope, revelaram que o artefato continha alguns tokens com formato de cones e outros com ovoides, encontrado perto de Dhahran na Arábia Saudita, conforme figura 9. 
Figura 9: Análise de um envelope com equipamento de Raio $X$

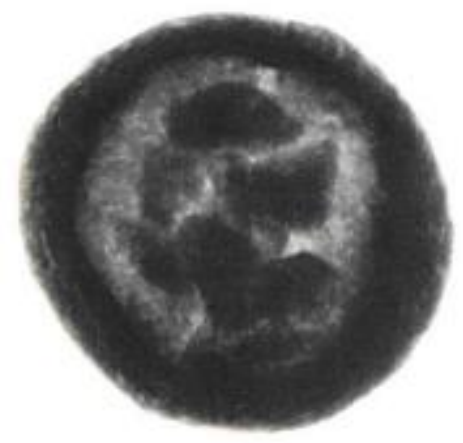

Fonte: Schmandt-Besserat (1977)

Essa análise rudimentar com o uso de equipamento de Raio $\mathrm{X}$, permitiu que os arqueólogos tivessem uma imagem do interior do envelope sem quebrá-lo, porém, com pouca precisão de seu conteúdo.

O pesquisador de imagens Borel (1995), apresentou uma sequência de imagens de um envelope de argila, utilizando equipamento de tomodensitometria, entretanto, percebe-se que as imagens, conforme a sequência da figura 10, ainda não ofereceram um nível de resolução e nitidez necessárias para o entendimento exato do número e do tipo de tokens que estão no seu interior.

Figura 10: Sequência de imagens de um envelope com equipamento de Tomodensitometria
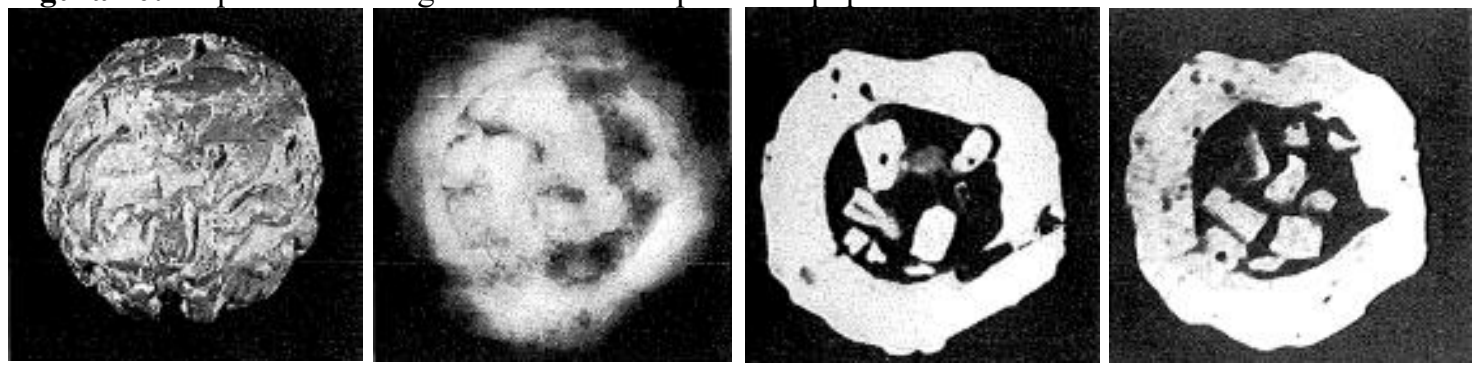

Fonte: Borel (1995)

Essas tentativas de análise não invasivas dos envelopes buscaram preservar as peças históricas, porém esbarraram em tecnologias com pouca capacidade investigativa. Pela sequência de imagens é perceptível a existência dos tokens no interior do envelope, mas o formato exato para tentar identificar seus significados, ainda careciam de aprimoramento. Para Jarus (2013), na busca de mais qualidade na geração de imagens das peças analisadas, pesquisadores de restos de sítios arqueológicos passaram a utilizar técnicas mais sofisticadas, como tomografia computadorizada de alta resolução e modelagem em terceira dimensão, atuando em um novo ambiente definido como Ciberarquelogia.

\subsection{A Ciberarqueologia e a Análise dos Tokens e dos Envelopes de Argila}

O uso de tecnologias cibernéticas digitais criou novas perspectivas investigativas para estudos históricos, especialmente em áreas como a arqueologia.

A Arqueologia Cibernética, ou Ciberarqueologia, de acordo com Forte (2010), está incorporando várias tecnologias nos seus processos investigativos, tais como a digitalização a laser 3D, o sensoriamento remoto, o uso de sistemas de posicionamento global (GPS) e sistemas de informação geográfica (GIS), o uso de fotogrametria e de modelagem computacional, especialmente para coletar e documentar artefactos históricos. Para Forte (2010), o processo de reconstrução virtual integra uma camada complexa de dados arqueológicos, históricos e culturais, possibilitando o fornecimento de ferramentas para que os 
pesquisadores possam visualizar, analisar e testar os dados históricos de forma mais consistente.

A Ciberarqueologia representa, segundo Forte (2012) a evolução pós-moderna da arqueologia virtual. Explica Forte (2012) que a arqueologia virtual direcionou sua atenção para a reconstrução 3D de modelos do passado, ao contrário da Ciberarqueologia que está sendo voltada para o desenvolvimento de mundos cibernéticos interativos e imersivos, concebida a partir da fusão dos últimos desenvolvimentos em ciência da computação, engenharia e ciências duras com a arqueologia.

Arqueologia Virtual, explica Forte (2012), teve origem na década de 1990, reconstruindo o passado com o uso de computação gráfica e renderizações de alta resolução na geração de mundos virtuais. A Arqueologia Cibernética, complementa Forte (2012), incorpora ferramentas avançadas de design de interação, de jogos de computador on-line, serious games, ambientes imersivos e comunidades virtuais. Na Ciberarquelogia existe uma maior interação e troca de informações entre os usuários e o ciberespaço, ao contrário do que era trabalhado na Arqueologia Virtual, onde a interação dos seres humanos com os ambientes virtuais era muito limitado.

Forte (2012), ressalta que na Arqueologia Digital, a maioria dos dados eram analógicos e somente em uma segunda etapa seriam digitalizados, ao contrário da Ciberarqueologia, que, em virtude da ampla utilização de scanners a laser, fotogrametria digital, visão computacional e tecnologias de sensoriamento remoto, os dados nascem digitais e geralmente são capturados por levantamento indireto ou instrumentos remotos.

O mundo cibernético vivido pela arqueologia, onde a hiper-realidade é uma condição central do processo de análise do mundo, tem a capacidade, segundo Forte (2012), de enriquecer, transformar e transfigurar a realidade, disseminando réplicas digitais, modelos e experiências virtuais, em um processo analítico não invasivo.

O uso dessas novas tecnologias facilita a conservação dos artefatos históricos analisados, por possuir características menos invasivas, que, segundo Motta (2017), permite que pesquisadores obtenham imagens virtuais, possibilitando uma profunda análise das peças, especialmente quando são utilizados tomógrafos computadorizados capazes de gerar arquivos virtuais tridimensionais. Esses arquivos em 3D permitem a prototipagem e a criação de réplicas com as mesmas características dos originais.

O uso dessa tecnologia e da transformação dos dados em modelos tridimensionais, embora seu uso seja mais comum no campo da medicina, é novo no campo arqueológico. Matsuura (2017, p.1), afirma que "provas de que a tecnologia vem revolucionando a arqueologia são recentes".

Dentro desse novo ambiente de análise histórica com uso de alta tecnologia, desde de 2011 uma equipe de pesquisadores da Universidade de Chicago tem utilizado vários equipamentos cibernéticos buscando aprofundar o entendimento dos tipos e funções dos tokens e dos envelopes de argila utilizados pela sociedade pré-histórica.

De acordo com Woods (2012), o processo de análise iniciou com múltiplos exames de alta resolução aplicados nos envelopes de argila, buscando a identificação das peças que estavam inseridas em seu interior. O processo iniciou, conforme Woods (2012), com a aplicação de radiografias 2D (conforme figura 11), combinadas com a criação de imagens de Tomografia Computadorizada 3-D (conforme figura 12). 
Figura 11: Imagem de radiografia de um envelope

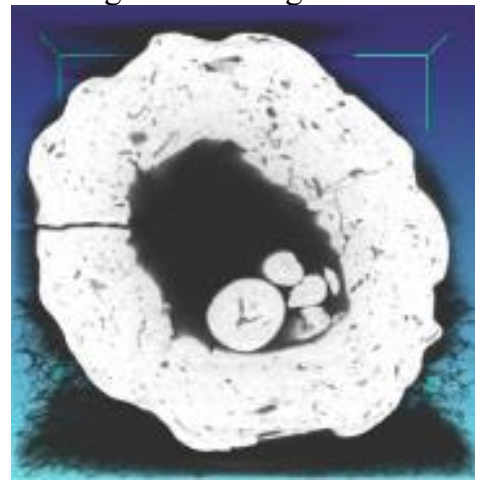

Fonte: Cortesia do The Oriental Institute of the University of Chicago. Woods (2012, p. 6)

Figura 12: Imagem de Tomografia Computadorizada 3-D do interior de um envelope

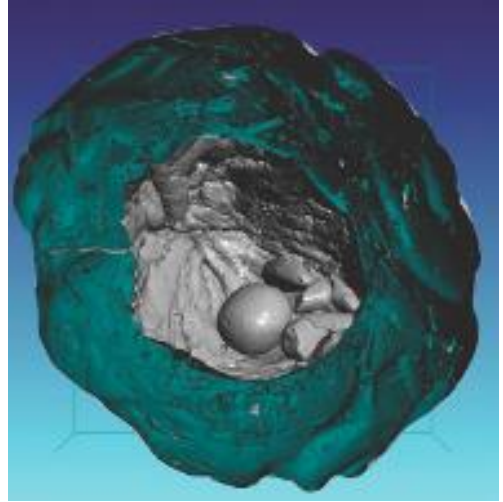

Fonte: Cortesia do The Oriental Institute of the University of Chicago. Woods (2012, p. 6)

A imagem da figura 12 permite que se tenha uma representação de alta resolução do envelope, apresentando nitidamente os diferentes tipos de tokens que foram armazenados no seu interior, exibindo o volume e a massa de cada ficha de argila. A partir dessa imagem, afirma Woods (2012), os envelopes digitalizados podem ser manipulados em espaço 3-D, dissecados e inspecionados quanto ao conteúdo, construção e composição da argila, com alto grau de precisão. A figura 13 apresenta a projeção em 3-D do envelope inteiro a partir das imagens geradas nas figuras 11 e 12.

Figura 13: Imagem de Tomografia Computadorizada 3-D do exterior de um envelope

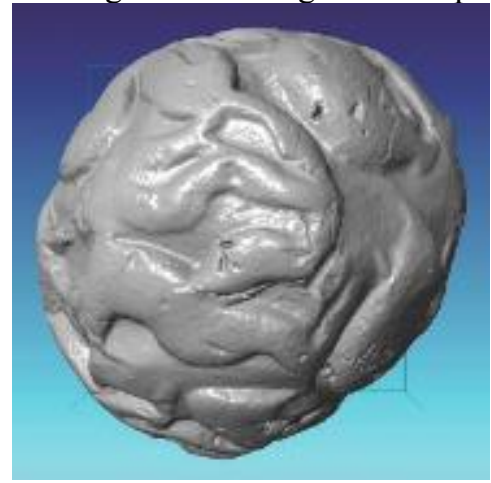

Fonte: Cortesia do The Oriental Institute of the University of Chicago. Woods (2012, p. 6)

A partir das imagens tridimensionais do envelope e de seu interior, foi possível remover digitalmente os tokens dos envelopes, permitindo que fossem realizadas análises dos tipos, tamanhos, formatos e demais características das peças sem que o envelope fosse danificado, conforme figuras 14 e 15. 
Figura 14: Imagem Tridimensional do exterior de um envelope

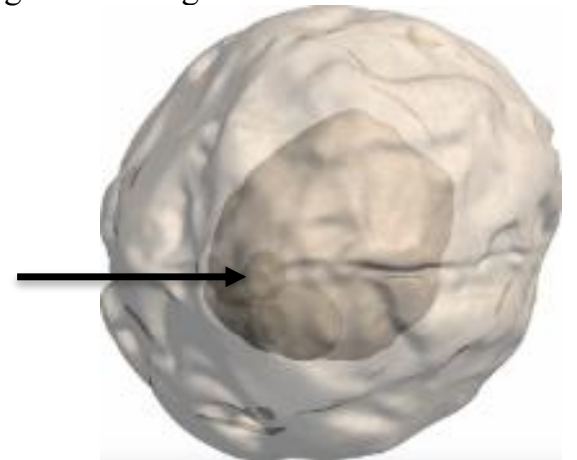

Fonte: Cortesia do The Oriental Institute of the University of Chicago. Woods (2012, p.7)

$\mathrm{Na}$ figura 15 é possível identificar todos os tokens armazenados no interior do envelope, sem que o artefato seja destruído para essa descoberta. Esses tokens estão assinalados pela seta na figura 17. Essa possibilidade de visualização era impossível a poucos anos atrás. A análise dependia da quebra da peça e, consequentemente, da perda do envelope. Com essa tecnologia os pesquisadores não têm mais limites do número de vezes que desejam analisar as peças, além de terem a possibilidade de aprofundarem seus estudos em termos milimétricos e detalhados.

Figura 15: Imagem de Tridimensional dos Tokens armazenados no envelope

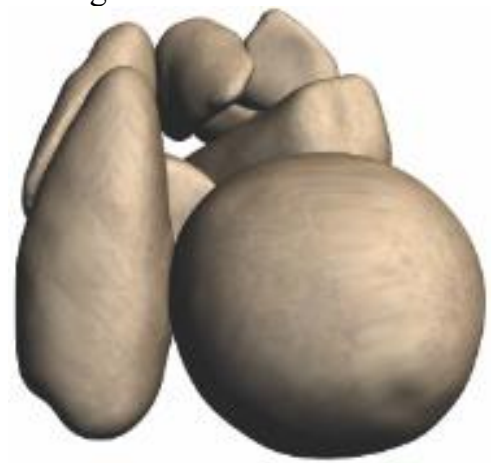

Fonte: Cortesia do The Oriental Institute of the University of Chicago. Woods $(2012$, p.7)

Para Woods (2012), os benefícios de escanear os envelopes, ao contrário de quebrálos, não é apenas pela natureza não-destrutiva dos testes, mas pela capacidade de inspecionar a estrutura interna da argila, permitindo inspecionar as dobras, as inclusões e as mudanças de densidade na argila que produzem indícios claros de como esses artefatos foram construídos. Nessas análises, acrescente Woods (2012), ficam aparentes os diferentes métodos que foram empregados para selar os envelopes, as várias qualidades da argila empregadas e as formas de fabricação das peças. Com isso, a análise dos referenciais dos bens controlados pelos tokens, torna-se mais consistente.

A figura 16 apresenta uma análise de um envelope com o uso de Tomografia Computadorizada 3-D, que permite que se observe os detalhes da dimensão do envelope (um pouco mais de $3 \mathrm{~cm}$ ), com destaque para os tokens de argila colocados no seu interior. 
Figura 16: Imagem de Tridimensional de um envelope com Tokens

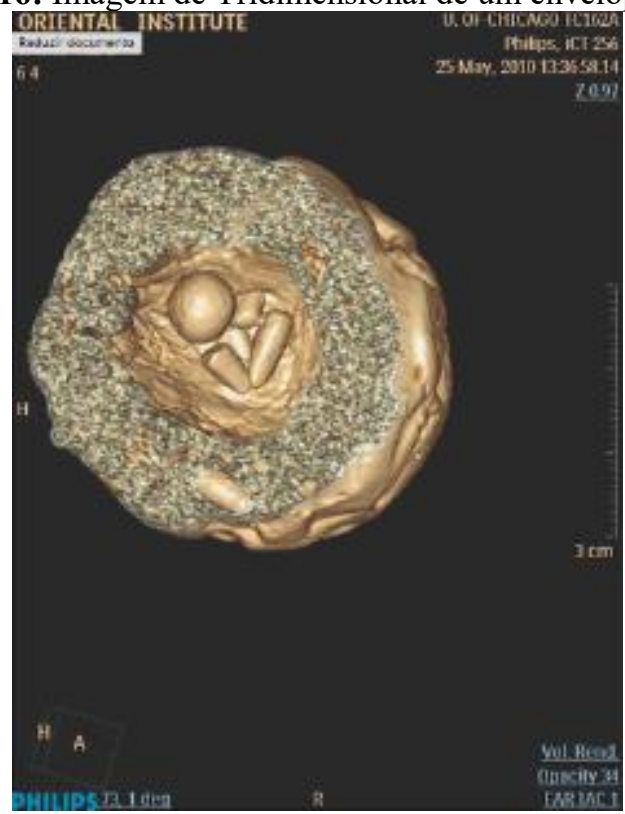

Fonte: Cortesia do The Oriental Institute of the University of Chicago. Woods (2015, pg. 48)

Essas ferramentas de alta definição têm revelado detalhes dos envelopes que seriam imperceptíveis em uma análise arqueológica tradicional. Woods (2015) destaca a análise de um envelope em que foram identificados minúsculos canais que cruzam o artefato, medindo 1 a 2 milímetros de largura, que talvez tenham sido utilizados para a inserção de fios para prender rótulos, possivelmente feitos de cera, que informavam quais tokens estavam dentro dos envelopes de argila. Esse detalhamento sem o uso de equipamentos de alta resolução não seria possível.

Segundo Woods (2015), alguns pesquisadores ficaram perplexos quando, após uma análise tomográfica de um envelope, encontraram tokens de argila junto com de um material de baixa densidade, provavelmente betume e, com um estudo mais aprofundado por meio da análise tridimensional da cavidade, descobriram um elemento estranho com a aparência de uma ameba. Em torno desses tokens, complementa o pesquisador, haviam bolhas de ar, sugerindo que os tokens foram enrolados em um pano antes de serem colocados no envelope, mesmo que o pano já tenha se desintegrado ao longo do tempo. Além disso, constataram que um líquido, provavelmente betume líquido, foi derramado sobre os tokens após terem sido inseridos nos envelopes. Um dos mais remotos registros do uso do betume, segundo Cesaret (2009), reside nos povos pré-babilônicos e em outros povos posteriores como os sumérios, no sudeste da Mesopotâmia.

Além do uso dessas novas tecnologias para análise dos artefatos de argila, o cientista David A. Kingery, do Instituto de Tecnologia de Massachusetts, como aponta SchmandtBesserat (1977), utilizou no exame de tokens microscópios eletrônicos e testes baseados em análise térmica diferencial, para identificar a forma que os artefatos eram endurecidos e concluiu que as peças teriam sido submetidas a uma temperatura de $600^{\circ}$ a $700^{\circ}$ centígrados.

\subsection{Contribuição das Ferramentas Cibernéticas na Análise de Tokens e Envelopes}

Conforme já destacado, esse estudo busca analisar como essas novas ferramentas cibernéticas estão contribuindo para o aprofundamento da compreensão de como os tokens e os envelopes de argila eram utilizados como ferramentas de controle contábil instituídos pelos homens pré-históricos. Para isso, é basilar entender de que forma a passagem da tecnologia analógica para a digital pode ter impactado na análise dessas ferramentas contábeis. 
Enquanto a análise era analógica, como destaca Franco (2011), o formato do armazenamento dos dados necessitava de um suporte físico e eram registrados em correspondência com o real. Franco (2011) apresenta um exemplo ilustrando essa realidade: as câmeras fotográficas analógicas necessitam de um filme para o registro da informação em exposição - a cena fotografada, sendo possível visualizar, direcionando o negativo do filme à luz, a imagem registrada, armazenada. Por outro lado, complementa Franco (2011), na tecnologia digital os dados são transformados em sinais binários (bits) e transformados em números, sem nenhuma correspondência análoga com o conteúdo da informação armazenada e, por isso, necessita de um suporte eletroeletrônico para ser visualizado.

A digitalização das imagens dos tokens e dos envelopes permite que a comunidade acadêmica tenha acesso mais fácil aos documentos, catálogos, repositórios, banco de dados, sem que as peças saiam dos museus de todo mundo. Para muitos acadêmicos seria impossível visualizar as peças contábeis históricas sem esse processo de digitalização. Além disso, a própria degradação das peças com o passar do tempo e com a manipulação pelos pesquisadores pode ser reduzida com a digitalização e a impressão em 3D.

A digitalização está alterando a própria forma com que os Museus estão se relacionando com os usuários. Alguns museus virtuais (Virtual Heritage) permitem que interessados façam passeios virtuais (walkarounds) em seus acervos.

Como defende Sanchotene (2007, pg. 63), o Virtual Heritage pode "disseminar a informação nos campos da história e da arqueologia para pesquisadores, restauradores, arquitetos, planejadores e administradores públicos e privados, além de permitir o seu uso no turismo virtual, através da Web ou multimídias interativas".

$\mathrm{O}$ The Oriental Institute of the University of Chicago (https://oi.uchicago.edu/sites/oi.uchicago.edu/files/uploads/tourfiles/index.html), por exemplo, faz um trabalho, como já destacado, que utiliza vários equipamentos cibernéticos na busca do aprofundamento do entendimento de como eram utilizados tokens e envelopes de argila como ferramentas de controle na pré-história. Esse museu permite um passeio virtual por seus acervos dentro desse conceito de Virtual Heritage.

A análise tomográfica, conforme Zolnerkevic e Fioravant (2016), permite que os pesquisadores identifiquem detalhes micrométricos do interior de peças arqueológicas sem precisar danificá-las, preservando os objetos e possibilitando a geração de informações que podem ser usadas para criar modelos tridimensionais. Para Motta (2017), o uso dessas novas tecnologias possibilita o acesso a informações e a detalhes da estrutura das peças históricas que dificilmente seriam encontrados a olho nu e com o uso de técnicas convencionais.

Figura 17: Imagem de reprodução de tokens e envelopes em tamanho real

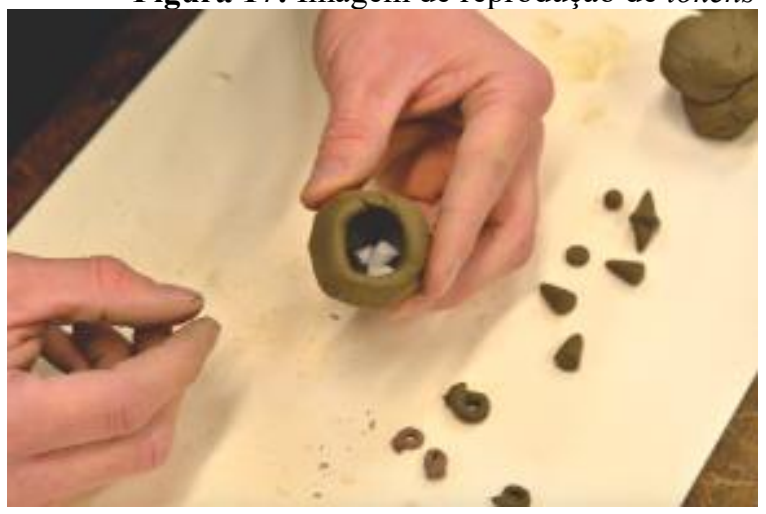

Fonte: Cortesia do The Oriental Institute of the University of Chicago. Woods (2012,pg. 7)

A partir desses detalhes micrométricos identificados nas análises tomográficas, foi possível que pesquisadores do The Oriental Institute of the University of Chicago reproduzissem 
tokens e envelopes de argilas, semelhantes aos utilizados na pré-história, conforme figura 17.

Esse processo reconstrutivo, como defendem Harrison e Dourish (1996), só foi possível com a criação dos espaços cibernéticos (cyberplace). Porém, mesmo que os objetos históricos sejam digitalizados, nem sempre o passado é suficientemente traduzido para validar a reconstrução na sua integralidade. A simulação pode mudar a forma como o pesquisador analisa o passado. Analisando a figura 20, por exemplo, é possível que se tenha uma ideia do formato e do tamanho dos tokens e de um envelope. A visualização das peças prototipadas pode mudar completamente a forma como pesquisador percebe a peça analisada. A possibilidade de poder visualizar os tokens e os envelopes em um ambiente virtual, permite que os estudiosos de História da Contabilidade experimentem a sensação de explorar, aprender, avaliar e explorar a origem das ferramentas de controle de uma forma mais interativa e prática.

Não somente a simulação real dos tokens e dos envelopes muda a compreensão do pesquisador, mas a hiper-realidade das comunidades virtuais possibilita uma maior interação com o passado, estimulando a busca por novos conhecimentos. Essa nova realidade virtual pode estimular que interessados no estudo da história busquem novos caminhos para desvendar a verdadeira origem da Contabilidade.

\section{Considerações Finais}

Esse estudo focou sua análise na forma como as novas ferramentas cibernéticas, dentro de um ambiente interativo, estão contribuindo para a identificação e descrição na busca do refinamento da compreensão de como os tokens e os envelopes de argila utilizados na préhistória eram empregados como ferramentas de controle.

A pesquisa bibliográfica e de documentos adotada nesse ensaio teórico, buscou ampliar a análise histórica tradicional focada no princípio do controle patrimonial e no uso de contas contábeis para controle da gestão. A Contabilidade, com seus instrumentos de controle primitivos, pode ter participado diretamente da evolução humana. O homem pré-histórico criou ferramentas de controle para o seu patrimônio, podendo ter dado início aos primeiros sinais de que a Contabilidade primitiva já participava diretamente da sociedade pré-histórica, embora esse não seja o foco desse ensaio teórico.

Mesmo que não exista unanimidade de que os tokens tenham dado origem a escrita cuneiforme, como defende Schmandt-Besserat (1992), a importância desses artefatos para a Contabilidade é inegável. Mesmo que posições como a de Michalowski (1993), ao afirmar que a escrita cuneiforme é um desenvolvimento separado como um sistema único e distinto, mas que pode ter sido influenciado pelos tokens, pelos envelopes e pelos selos muito utilizados na antiga Mesopotâmia. Mesmo assim, isso não diminui o valor dos tokens e dos envelopes como ferramentas de controle patrimonial e de elementos úteis para a sociedade pré-histórica e para auxiliar na compreensão da gênese da Contabilidade.

Opiniões como a de Zimansky (1993) ao afirmar que um grande obstáculo nos testes da teoria de Schmandt-Besserat é entender estes artefatos contabilísticos, em função da incapacidade de analisar de uma maneira fácil o conteúdo da grande maioria dos envelopes de argila, podem ser minimizadas com a inclusão de ferramentas de alta tecnologia no processo de análise dos artefatos de argila. O uso da tecnologia 3D permite que os objetos sejam manipulados em tempo real, analisados sob várias perspectivas, expandidos, detalhados, visualizados on-line em qualquer parte do mundo, sem que exista a necessidade da peça física estar disponível para estudo.

A busca pelas as primícias da Contabilidade, passa a estar disponível para qualquer estudioso de História da Contabilidade. A visualização das peças, em alta resolução, facilita a percepção dos detalhes dos tokens e dos envelopes. A possibilidade de atualização para 
mundo contábil a partir da descoberta de novas peças pré-históricas, faz com que o estudo da história seja dinâmico e de fácil acesso.

Como afirma Person (2017), é possível dizer que os envelopes foram as primeiras planilhas contábeis ou dashboards, pois, era possível verificar quais ativos estavam sendo arquivados e quais alterações ocorreram no sistema de inventário, caso o envelope fosse quebrado, com a mudança do número de tokens armazenados no seu interior. Hoje, com o uso das novas ferramentas cibernéticas, não é mais necessário destruir o envelope para que se tenha acesso aos tokens. Essa nova realidade de investigação científica e tecnológica tem contribuído para o aprimoramento da compreensão da forma como os tokens e, principalmente, os envelopes de argila eram utilizados como ferramentas de controle contábil pela sociedade pré-histórica.

Essas novas ferramentas cibernéticas possibilitam a disseminação dos estudos com a produção de novos materiais didáticos, que podem auxiliar no ensino da História da Contabilidade de forma mais prática e poderá significar no futuro um instrumento indispensável para os estudos e pesquisas históricas.

Como o uso dessas ferramentas de alta tecnologia são recentes no campo histórico, futuros estudos poderão ampliar o entendimento de instrumentos contábeis históricos, como, por exemplo: uma análise do impacto do walkarounds dos museus virtuais no estudo da Contabilidade; um estudo sobre a datação da origem dos Quipus incaicos com do uso do carbono 14; um estudo sobre os documentos contábeis disponibilizados no acervo virtual do Museu Nacional da Universidade Federal do Rio de Janeiro.

\section{Referências}

ANTÓN, S. C., POTTS, R. \& AIELlO, L. C. Evolution of early Homo: An integrated biological perspective. Science, Vol. 345, no. 6192, 4 July 2014.

AZEVEDO NETTO, Carlos X.; SOUZA, Amilton J. A importância da cultura material e da Arqueologia na construção da História. História Unisinos, v. 14, n. 1, p. 62-76, 2010.

BARROS, José D.' Assunção. Teoria da história: Volume I. Princípios e conceitos fundamentais. Petrópolis: Vozes, 2011.

BOREL, Thierry. La radiographie des objets d'art. Technè, v. 2, p. 146-157, 1995.

BUCCELLATI, G. Antecedents of writing. Disponível em: http://www.urkesh.org/excurs/writing.htm.

BURKE, J. \& ORNSTEIN, R. Turning Points in the Development of Contemporary Society. A report on The Axe maker's Gift Technology's Capture and Control of Our Minds and Culture. 2017. Disponível em: http://www.humanjourney.us/axemaker.html.

BURKE, Peter. A história dos acontecimentos e o renascimento da narrativa. A Escrita da História $\square$ novas perspectivas, p. 327-348, 1992.

CARMONA, Salvador; EZZAMEL, Mahmoud; GUTIÉRREZ, Fernando. Accounting history research: traditional and new accounting history perspectives. De Computis-Revista Española de Historia de la Contabilidad, v. 1, n. 1, p. 24-53, 2016.

CARNEGIE, Garry D. e NAPIER, Christopher J. Historiography in Accounting Research. Final draft of Chapter 5 in The Routledge Companion to Qualitative Accounting Research Methods, edited by Zahirul Howue, Lee D. Parker, Mark Covaleski and Kathryn Haynes, Abingdon: Routledge, 2016. 
CESARET, M. É factível que a arca do livro de Gênesis tenha sido calafetada com betume? Fides reformata XIV, São Paulo, nº 1, 47-73, 2009.

FONTOURA, Yuna; ALFAIA, Lilian; FERNANDES, Alexandre. A pesquisa histórica em estudos organizacionais no Brasil: uma análise paradigmática e novas perspectivas. Revista Eletrônica de Gestão Organizacional, v. 11, n. 1, 2013.

FORTE, Maurizio (Ed.). Cyber-archaeology. Oxford: Archaeopress, 2010.

FORTE, Maurizio. Cyberarchaeology: a Post-Virtual Perspective. Humanities and the Digital. A Visioning Statement. MIT Press. Boston, 2012.

FRANCO, Nerilda da Costa, Tecnologia analógica e digital. 2011. Disponível em: http://nerildafranco.blogspot.com.br/2011/06/tecnologia-analogica-e-digital 16.html

HARRISON, Steve; DOURISH, Paul. Re-place-ing space: the roles of place and space in collaborative systems. In: Proceedings of the 1996 ACM conference on Computer supported cooperative work. ACM, p. 67-76, 1996.

HOPWOOD, A. G. The archeology of accounting systems. Accounting, organizations and society, v. 12, n. 3, p. 207-234, 1987.

JARUS, O. Clues to Lost Prehistoric Code Discovered in Mesopotamia. Live Science. October 10, 2013.

LAWLER, A. Writing Gets a Rewrite. Science. Vol. 292, no.5526, p. 2418-2420, 2001.

MACGINNIS, J. et al. Artefacts of Cognition: The Use of Clay Tokens in a Neo-Assyrian Administration. Cambridge Archaeological Journal, v. 24, n. 02, p. 289-306, 2014.

LINS, Consuelo; REZENDE, Luiz Augusto; FRANÇA, Andréa. A noção de documento e a apropriação de imagens de arquivo no documentário ensaístico contemporâneo. Revista Galáxia, n. 21, 2011.

MARK, J. J. The Ancient City, 2017. Disponível em: http://www.ancient.eu/city/.

MARTÍN, Fabián Leonardo Quinche. Historia de la Contabilidad: Una revisión de las Perspectivas. Revista Facultad de Ciencias Económicas: Investigación y Reflexión, v. 14, n. 1, p. 187-201, 2006.

MARTIRE, Alex da Silva. DOMUS: Cyber-Archeology in Three-Dimensional Virtual Environment. In: Virtual and Augmented Reality (SVR), 2014 XVI Symposium on. IEEE, p. 148-155, 2014.

Ciberarqueologia em Vipasca: o uso de tecnologias para a reconstruçãosimulação interativa arqueológica. Tese de Doutorado. Universidade de São Paulo. 2017.

MATSUURA, Sérgio. Tecnologia revoluciona descoberta arqueológicas. 2017. Disponível em: https://oglobo.globo.com/sociedade/tecnologia/tecnologia-revoluciona-descobertasarqueologicas-17941276\#ixzz4h9I2Gbbc.

MATTESSICH, Richard. Prehistoric accounting and the problem of representation: On recent archeological evidence of the Middle-East from $8000 \mathrm{BC}$ to $3000 \mathrm{BC}$. The Accounting Historians Journal, p. 71-91, 1987.

.Accounting and the input-output principle in the prehistoric and ancient world. Abacus, v. 25, n. 2, p. 74-84, 1989. 
Archaeology of accounting and Schmandt-Besserat's contribution. Accounting,

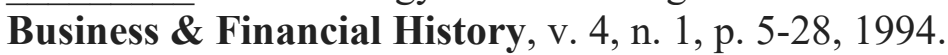

. Kautilya's Arthasastra. a Sanskrit treatise, formulating modern accounting issues some 2.300 years ago, trabalho encaminhado pelo Centro de Estudos de Historia da Contabilidade, da APOTEC. 1997.

. Recent insights into Mesopotamian accounting of the 3rd millennium BCsuccessor to token accounting. The Accounting Historians Journal, p. 1-27, 1998.

. The beginnings of accounting and accounting thought: accounting practice in the Middle East (8000 BC to $2000 \mathrm{BC}$ ) and accounting thought in India (300 $\mathrm{BC}$ and the Middle Ages). Taylor \& Francis, 2000.

MENEGHETTI, Francis Kanashiro. O que é um ensaio-teórico?. RAC-Revista de Administração Contemporânea, v. 15, n. 2, 2011.

MICHALOWSKI, P. T. Review article of D. Schmandt-Besserat, Before Writing. American Anthropologist, 95, pg. 996-999, 1993.

MORENO, José Carlos. Do Analógico ao Digital: Como a digitalização afeta a produção, distribuição e consumo de informação, conhecimento e cultura na Sociedade em Rede. Observatório (OBS*), v. 7, n. 4, p. 113-129, 2013.

MOTTA. Débora. Acervo do Museu Nacional ganha réplicas em 3D a partir da prototipagem rápida. 2017. Disponível em: http://www.faperj.br/?id=1372.2.5.

NGO, Robin. Mesopotamian "Receipts" Illuminated by 3D Technology. Biblical Archaeology Review. 2017. Disponível em: http://www.biblicalarchaeology.org/daily/ancient-cultures/ancient-near-easternworld/mesopotamian-receipts-illuminated-by-3d-technology/.

OLIVEIRA, Maria Marly de. Como fazer pesquisa qualitativa. São Paulo, Vozes, 2016.

PADILHA, Maria Itayra Coelho de Souza; BORENSTEIN, Miriam Süsskind. O método de pesquisa histórica na enfermagem. Texto \& Contexto Enfermagem, v. 14, n. 4, p. 575-584, 2005.

PERSON, R. Web analytics series: from cave walls to clickstream to engagement value. 2015. Disponível em: https:/www.sitecore.net/learn/blogs/best-practice-blogs/ronperson/posts/2011/01/web-analytics-series-clickstream-and-engagement.aspx.

PIMENTEL, Alessandra. O método da análise documental: seu uso numa pesquisa historiográfica. Cadernos de pesquisa, v. 114, p. 179-195, 2001.

RANGEL, Danny; ALMEIDA, Nelson. A Arqueologia na Era Digital: Contexto e tendências/Archaeology in the Digital Age: Context and Trends. Revista Internacional de Ciencias Humanas, v. 1, n. 2, 2012.

ROBSON, E. Accounting for change: The development of tabular bookkeeping in early Mesopotamia. Creating economic order: Record-keeping, standardization, and the development of accounting in the Ancient Near East, p. 107-144, 2004.

SÁ-SILVA, Jackson Ronie; ALMEIDA, Cristóvão Domingos de; GUINDANI, Joel Felipe. Pesquisa documental: pistas teóricas e metodológicas. Revista brasileira de história \& ciências sociais, v. 1, n. 1, 2009.

SANCHOTENE, Isolina Severo. Técnicas de virtual heritage (VH) e as legislações brasileiras aplicadas ao patrimônio cultural-Estudo de Caso: Campo de Sant'Anna. 
Dissertação de Mestrado em Ciências em Engenharia Civil, COPPE, UFRJ, Rio de Janeiro, 2007.

SCHMANDT-BESSERAT D. An Archaic Recording System and the Origin of Writing. Syro-Mesopotamian Studies, v. 1, n. 2, p. 1-32, 1977.

. Reckoning before writing. Archaeology New York, NY, v. 32, n. 3, p. 22-31, 1979.

.. Conto e Contabilita nel Medio Oriente Prehistorico. F. Mario Fales, ed. Prima Dell'Alphabeto, Studi e Documenti, V. 4, Erizzo, Venice, P. 54-60, 1989.

Press. 1992.

.D. Before writing, from counting to Cuneiform. v. 1. University of Texas

.Dal Cantabile Scriture. Le Scienze, Roma,12, p.16-20, 2002.

.Tokens and Writing: the Cognitive Development. Scripta, University of Texas at Austin, Volume 1 145-154, September 2009a.

Record Keeping before Writing, Marco Mancini and Barbara Turchetta, Eds., Scrittura e Scriture: Le Figure della Lingua. Atti del XXIX Convegno della Societa Italiana di Glottologia, Il Calamo, Roma.P. 67-80, (2009b.

.. The Token System of the Ancient Near East: its Role in Counting, Writing, the Economy and Cognition. Colin Renfrew, eds. The Archaeology of Measurement, Comprehending Heaven, Earth and Time in Ancient Societies, Cambridge University Press, Cambridge, p. 27-34. 2010.

.Tokens as Precursors of Writing. in Elena L. Grigorenko, Elisa. Mambrino, David D. Preiss, eds. Writing: a Mosaic of New Perspectives, Psychology Press, New York, P. 3-1, 2012.

.Tokens - Reallexikon der Assyriologie und Vorderasiatischen Archaeologie. Lieferung, Vol. 14 1/2. De Gruyter, Berlin, P. 87-8, 2014.

SEVERINGHAUS, J. P. \& Brook, E. J. Abrupt Climate Change at the End of the Last Glacial Period Inferred from Trapped Air in Polar Ice. Science, Vol. 286 no. 5441, pp. 930-934, 29 October 1999.

SCHØYEN, M. An academic \& educational resource from the private collection neolithic counting tokens. 2017a. Disponível em: http://www.schoyencollection.com/mathematics-collection/pre-literate-counting/neolithiccounting-tokens-ms-5067-1-8.

.An academic \& educational resource from the private collection - complex counting tokens. 2017b. Disponível em: http://www.schoyencollection.com/mathematicscollection/pre-literate-counting/complex-counting-tokens-ms-4522-1.

.. An academic \& educational resource from the private collection. - bullaenvelope: 11. 2017c. Disponível em: http://www.schoyencollection.com/mathematicscollection/pre-literate-counting/bulla-envelope-ms-4631.

.An academic \& educational resource from the private collection - bullaenvelope. 2017d. Disponível em: http://www.schoyencollection.com/mathematicscollection/pre-literate-counting/bulla-envelope-ms-4632.

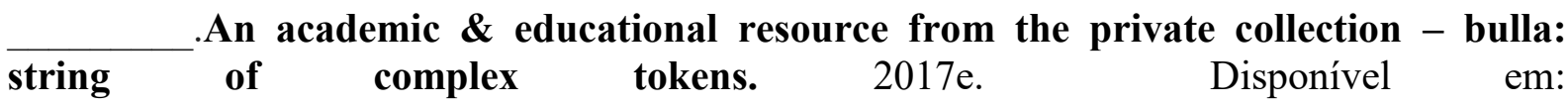


http://www.schoyencollection.com/mathematics-collection/pre-literate-counting/bulla-stringtokens-ms-4523.

SCHROEDER, F. E. H. Popular culture methodologies: a bibliographic afterword. 5000 Years of Popular Culture: Popular Culture Before Printing. Bowling Green State University Popular Press, Bowling Green, Ohio. 1980.

WOODS, Christopher. Early Writing and Administrative Practice in the Ancient Near East: New Technology and the Study of Clay Envelopes from Choga Mish. The Oriental Institute: News and Notes, v. 215, p. 3-8, 2012.

.Visible Language. Inventions of writing in the middle east and beyond. University Chicago, Oriental Institute Museum Publications, 32, Chicago, 2015.

ZIMANSKY, P. Review of Before Writing, Volume 1: From Counting to Cuneiform, by D. Schmandt-Besserat. Journal of Field Archaeology, 20: 513-17. 1993.

ZOLNERKEVIC, Igor; FIORAVANTI, Carlos. Por dentro dos fósseis. Tomografia por computador se torna mais disseminada e permite análises detalhadas de ossos de animais extintos. Pesquisa Fapesp, n. 246, p. 58-61, 2016. 